\title{
FENOLOGIA, BROTAÇÃO DE GEMAS E PRODUÇÃO DE FRUTOS DE MACIEIRA EM RESPOSTA À APLICAÇÃO DE CIANAMIDA HIDROGENADA E ÓLEO MINERAL $\left({ }^{1}\right)$
}

\author{
FERNANDO JOSÉ HAWERROTH $\left({ }^{*}\right)$; JOSÉ LUIZ PETRI $\left({ }^{3}\right)$; FLAVIO GILBERTO HERTER $\left({ }^{4}\right)$; \\ GABRIEL BERENHAUSER LEITE $\left({ }^{3}\right)$; JEISON FURTADO LEONETTI $\left({ }^{4}\right)$; \\ ANDERSON CARLOS MARAFON $\left({ }^{5}\right.$; FABIANO SIMÕES $\left({ }^{5}\right)$
}

\begin{abstract}
RESUMO
A aplicação de indutores de brotação é uma das principais estratégias de manejo utilizadas para minimizar os problemas da falta de frio em frutíferas de clima temperado. Em razão da influência dos indutores de brotação sobre a resposta produtiva das plantas, a mensuração de seus efeitos ao longo do ciclo produtivo torna-se importante. Assim, o presente trabalho foi desenvolvido no ciclo 2007/2008, em Caçador/SC, objetivando avaliar diferentes combinações de cianamida hidrogenada e óleo mineral sobre a fenologia, brotação de gemas e produção de frutos em macieiras. O delineamento experimental foi em blocos casualizados, com seis repetições compostas de uma planta, seguindo arranjo fatorial (5x2), com cinco níveis de indutor de brotação (1. testemunha; 2. óleo mineral 3,2\%; 3. óleo mineral 3,2\% + cianamida hidrogenada $0,20 \%$; 4 . óleo mineral 3,2\% + cianamida hidrogenada 0,39\%; 5 . óleo mineral 3,2\% + cianamida hidrogenada 0,59\%) e duas cultivares (Imperial Gala e Fuji Suprema). A aplicação dos indutores de brotação antecipou e reduziu o período de florescimento, aumentando a coincidência de florescimento das cultivares Imperial Gala e Fuji Suprema. Os indutores de brotação uniformizaram e aumentaram a brotação de gemas axilares e terminais, obtendo-se máxima brotação na cultivar Imperial Gala com $0,44 \%$ de cianamida hidrogenada e 3,2\% de óleo mineral. O aumento da concentração de cianamida hidrogenada revelou a tendência de diminuir a frutificação efetiva. Observaram-se respostas diferenciadas entre tratamentos quanto à produção e à massa média dos frutos, podendo ser atribuídas ao predomínio da produção de frutos em distintas estruturas de frutificação.
\end{abstract}

Palavras-chave: dormência, indutores de brotação, Malus domestica.

( $\left.{ }^{1}\right)$ Recebido para publicação em 27 de agosto de 2008 e aceito em 14 de julho de 2009.

( $\left.{ }^{2}\right)$ Programa de Pós-graduação, Faculdade de Agronomia Eliseu Maciel, Universidade Federal de Pelotas (UFPel), 96010 900 Pelotas (RS), Brasil. E-mail: fjhawerroth@yahoo.com.br (*) Autor correspondente. Bolsista de Doutorado do CNPq.

$\left({ }^{3}\right)$ Estação Experimental de Caçador, Empresa de Pesquisa Agropecuária e Extensão Rural de Santa Catarina (Epagri), 89500-000 Caçador (SC), Brasil. E-mail: petri@epagri.sc.gov.br; gabriel@epagri.sc.gov.br

$\left({ }^{4}\right)$ Faculdade de Agronomia Eliseu Maciel, Universidade Federal de Pelotas (UFPel), 96010-900 Pelotas (RS), Brasil. E-mail: E-mail: flavioherter@gmail.com; jeisonleonetti@yahoo.com.br

$\left({ }^{5}\right)$ Programa de Pós-Graduação em Fisiologia Vegetal Universidade Federal de Pelotas (UFPel), Pelotas (RS), Brasil. E-mail: anderson.marafon@gmail.comE-mail: flavioherter@gmail.com ; simoesf@gmail.com 


\title{
ABSTRACT \\ PHENOLOGY, BUDBREAK AND APPLE FRUIT PRODUCTION BY HYDROGEN CYANAMIDE AND MINERAL OIL APPLICATION
}

\begin{abstract}
The budbreak promoters application is one of main management strategies used to decrease the problems of insufficient winter chilling on temperate fruit trees. Because the influence of budbreak promoters on productive behaviour of plants, detecting this effects along of productive season became important. Thus, this study was carried out during 2007/2008 season, in Caçador, Santa Catarina State, Brazil, aiming to evaluate different hydrogen cyanamide and mineral oil combinations on phenology, budbreak and apple fruit production. The experimental design was a randomized block, with six replications, in factorial arrangement $(5 \times 2)$, with five budbreak promoter treatments $(1$. control; 2 . mineral oil $3.2 \%$; 3 . mineral oil $3.2 \%$ + hydrogen cyanamide $0.20 \%$; 4 mineral oil $3.2 \%$ + hydrogen cyanamide $0.39 \%$; 5 . mineral oil 3.2\% + hydrogen cyanamide 0.59\%) and two cultivars (Imperial Gala and Suprema's Fuji). The budbreak promoters application anticipated and reduced the blooming period, increasing the blooming overlap between Imperial Gala and Suprema's Fuji cultivars. The budbreak promoters equalized and increased the budbreak in axillary and terminal buds, with the major budbreak level observed in Imperial Gala cultivar with $0.44 \%$ of hydrogen cyanamide and $3.2 \%$ of mineral oil treatment. The increase of hydrogen cyanamide concentration showed the tendency to decrease the fruit set. It was observed different treatment responses on production and mean fruit weight, probably to be related to fruit production predominance in different frutification structures.
\end{abstract}

Key words: dormancy, budbreak promoters, Malus domestica.

\section{INTRODUÇÃO}

A dormência é um fenômeno ocorrente em frutíferas de clima temperado, sendo um mecanismo adaptativo que permite sua sobrevivência em condições ambientais não favoráveis ao seu desenvolvimento. As plantas, para sobreviverem a períodos de estresse, como é o caso de baixas temperaturas hibernais, desenvolveram um mecanismo adaptativo que passa pela aquisição da resistência ao frio e do controle do crescimento (LeITE, 2005).

A brotação e o florescimento na cultura da macieira (Malus domestica Borkh.) manifestam-se normalmente quando cultivada em regiões com alta acumulação de frio durante o período de outono e inverno. Quando cultivada em regiões com insuficiente acúmulo de frio para atender suas necessidades fisiológicas, a macieira exibe brotação deficiente e desuniforme (Bulon e Faust, 1995; Petri et al.,1996; Erez, 2000; Petri e Leite, 2004), podendo reduzir o volume e a qualidade dos frutos produzidos.

Em regiões e em anos quando não ocorre adequado acúmulo de frio durante o inverno, problemas relacionados à não-sincronização do florescimento entre cultivares produtoras e suas respectivas polinizadoras manifestam-se com maior freqüência (Soltész, 2003), podendo repercutir em baixas produtividades devido a problemas de polinização em conseqüência da não-coincidência de floração.

No Brasil, as principais cultivares utilizadas pertencem aos grupos Gala e Fuji, sendo caracterizadas pela alta qualidade de frutos e alta exigência em frio. De acordo com PETRI et al. (1996) e PETRI et al. (2006), grande parte das regiões onde a cultura é explorada no país não proporciona atendimento do requerimento em frio destas cultivares, sendo necessário a adoção de práticas de manejo complementares para minimizar os problemas decorrentes da falta de frio.

A utilização de agentes químicos, visando à maximização da brotação de gemas e a uniformização da floração, é a prática de manejo mais difundida em regiões com baixo acúmulo de frio hibernal. Vários produtos químicos, incluindo reguladores de crescimento e componentes nutricionais, têm sido utilizados para a superação da dormência (EL-AGAmY et al., 2001), assegurando uniformidade na brotação na cultura da macieira (CARVAJAL-MILLÁn et al., 2007). Dentre os produtos disponíveis no mercado, a cianamida hidrogenada $\left(\mathrm{H}_{2} \mathrm{CN}_{2}\right)$ é o produto químico mais eficiente para maximizar a brotação de gemas em inúmeras espécies frutíferas decíduas (DoKOOzLIAN et al., 1995; Petri et al., 1996; Erez, 2000; Wlliamson et al., 2002).

No sistema brasileiro de produção de maçãs, a cianamida hidrogenada tem sido utilizada associada ao óleo mineral, permitindo redução da concentração de cianamida hidrogenada a ser aplicada. Segundo Petri (2005), a utilização de óleo mineral em mistura a outros indutores de brotação tem sido utilizada com eficiência, reduzindo o custo dos tratamentos para indução da brotação. Para PETRI et al. (1996), o uso de agentes químicos para indução da brotação pode antecipar a floração, especialmente no 
caso de cianamida hidrogenada e óleo mineral, alterando a sincronia da floração com as plantas polinizadoras.

Apesar de maior economia proporcionada pela adição de óleo mineral, a cianamida hidrogenada, a indução da brotação mediante uso de produtos químicos ainda é um item de grande custo na produção de maçãs no Brasil. A definição de doses adequadas destes produtos pode otimizar a brotação na macieira, assim como reduzir os riscos de contaminação ambiental. Dada a influência dos indutores de brotação no comportamento produtivo das plantas, estudos visando à mensuração de seus efeitos ao longo do ciclo produtivo até a frutificação tornam-se pertinentes.

O objetivo deste trabalho foi avaliar o desempenho de diferentes combinações de cianamida hidrogenada e óleo mineral sobre a fenologia, brotação de gemas e produção de frutos das cultivares de macieira Imperial Gala e Fuji Suprema.

\section{MATERIAL E MÉTODOS}

O experimento foi desenvolvido em pomar experimental localizado no município de Caçador, SC (latitude $26^{\circ} 46^{\prime} \mathrm{S}$, longitude $51^{\circ} \mathrm{W}$, altitude 960 metros), durante o ciclo 2007/2008. Segundo classificação de Köppen, o clima na região de cultivo é classificado como $\mathrm{Cfb}$ - temperado constantemente úmido, com verão ameno. A média da precipitação pluvial anual é de 1653,2 $\mathrm{mm}$ e a umidade relativa do ar média é de $77,9 \%$. Segundo Petri (2006), o acúmulo médio de frio durante o período de outono e inverno é de 1047,5 unidades de frio.

Utilizaram-se plantas de 12 anos de idade das cultivares Imperial Gala e Fuji Suprema, enxertadas sobre o porta-enxerto $\mathrm{M} / 26$. As cultivares Imperial Gala e Fuji Suprema são mutações somáticas das cultivares Gala e Fuji respectivamente. Segundo CAMilo e DenARdi (2006), essas cultivares diferem das cultivares que lhes deram origem pela maior intensidade e uniformidade da coloração nos frutos.

A densidade de plantio no pomar utilizado é de 2500 plantas $\mathrm{ha}^{-1}$, com espaçamento de $4 \mathrm{~m}$ entre linhas e $1 \mathrm{~m}$ entre plantas, sendo as plantas manejadas no sistema de condução em líder central. O esquema de polinização adotado baseava-se na utilização de duas cultivares produtoras, sendo Imperial Gala polinizadora da cultivar Fuji Suprema e vice-versa. Desde a implantação do experimento até o término da realização deste estudo, o pomar foi conduzido de acordo com as práticas de manejo recomendadas no sistema de produção da macieira (SANHUEZA et al., 2006).
Os tratamentos consistiram da aplicação de diferentes indutores de brotação em plantas das cultivares Imperial Gala e Fuji Suprema. O delineamento experimental utilizado foi em blocos casualizados, seguindo um arranjo fatorial $(5 \times 2)$ obtido da combinação de cinco níveis do fator indutor de brotação e dois níveis do fator cultivar. Foram utilizadas seis repetições, sendo cada uma composta por uma planta.

Os níveis estudados para o fator indutor de brotação foram: 1) testemunha (sem aplicação); 2) óleo mineral $3,2 \%$; 3) óleo mineral 3,2\% + cianamida hidrogenada $0,20 \%$; 4) óleo mineral $3,2 \%$ + cianamida hidrogenada $0,39 \%$; 5 ) óleo mineral 3,2\% + cianamida hidrogenada $0,59 \%$. Como fonte de cianamida hidrogenada e óleo mineral foram utilizados os produtos comerciais Dormex ${ }^{\circledR}(49 \%$ de ingrediente ativo) e Triona $^{\circledR}(80 \%$ de ingrediente ativo $)$ respectivamente.

A aplicação dos indutores de brotação foi realizada através de aspersão com pulverizador costal motorizado, com um volume médio de $1000 \mathrm{~L} \mathrm{ha}^{-1}$. Os tratamentos foram aplicados em 5/9/2007, quando já haviam sido acumuladas 876,46 unidades de frio segundo modelo Carolina do Norte modificado (EBERT et al., 1986), quantidade de frio insuficiente para a superação natural da dormência das cultivares estudadas, justificando a aplicação dos indutores de brotação.

Durante o período do experimento foram realizadas a avaliação da fenologia durante o período de floração, brotação de gemas axilares, brotação de gemas terminais, heterogeneidade da brotação de gemas axilares, frutificação efetiva, número e massa de frutos por área de secção transversal de tronco e massa média dos frutos.

A avaliação da fenologia do florescimento consistiu na determinação das datas de ocorrência das fases de início, plena e final de floração para cada tratamento. O início de floração foi considerado quando as plantas estavam com $5 \%$ de flores abertas, a plena floração quando verificado mais de $80 \%$ de flores abertas e o fim de floração foi dado quando as últimas flores estavam abertas.

A partir dos dados fenológicos obtidos, os períodos de floração foram comparados entre cultivares, dentro de cada nível do fator indutor de brotação, a fim de verificar a coincidência de floração existente entre as cultivares Imperial Gala e Fuji Suprema. Calculou-se o intervalo, em dias, compreendido entre a aplicação dos tratamentos e a data de início de floração. 
A brotação de gemas axilares foi obtida da contagem de gemas brotadas e não brotadas em cinco brindilas, previamente selecionadas, localizadas no terço médio da planta. A partir das observações destas cinco brindilas, foram obtidos os valores médios de brotação de gemas axilares e os desvios-padrão respectivos a cada tratamento, calculando-se os coeficientes de variação dentro de cada tratamento estudado. Os coeficientes de variação obtidos foram denominados índices de heterogeneidade da brotação de gemas axilares, sendo utilizados para comparar a uniformidade da brotação entre os tratamentos.

Uma ramificação lateral de cada planta foi selecionada para contagem de gemas terminais brotadas e não brotadas, para estimativa da porcentagem de brotação de gemas terminais. A brotação de gemas axilares e terminais foram avaliadas aos 27 dias após a aplicação dos tratamentos. A frutificação efetiva foi obtida da relação entre o número de frutos e número de cachos florais contados durante a plena floração ([número de frutos / cachos florais] $\times 100$ ), sendo as contagens realizadas na mesma ramificação lateral utilizada para estimar a brotação de gemas terminais.

Quando determinado o ponto de colheita, os frutos de cada planta foram colhidos, avaliando-se a massa e o número total de frutos por planta. A massa e o número de frutos por planta foram divididos pela área de secção transversal do tronco de cada planta, sendo expressos em $\mathrm{kg} \mathrm{cm} \mathrm{cm}^{-2}$ e em frutos $\mathrm{cm}^{-2}$ respectivamente. Pela relação entre a massa e o número total de frutos por planta foi estimada a massa média dos frutos, expressa em g.fruto ${ }^{-1}$.

As variáveis expressas em porcentagem foram transformadas através da equação $(x+5)^{1 / 2}$, a fim de atender as pressuposições da análise de variância (BANZATto e KRONKA, 1995). Os resultados foram submetidos à análise de variância e as variáveis que revelaram significância a 5\% de probabilidade de erro foram comparados pelo teste Tukey a 5\% de significância. Através da análise de regressão foram obtidas equações de regressão polinomial ajustadas, a fim de discriminar o efeito do aumento da concentração de cianamida hidrogenada associada ao óleo mineral sobre as variáveis avaliadas. As análises estatísticas foram realizadas no programa computacional SAS LEARNING EDITION (2002).

\section{RESULTADOS E DISCUSSÃO}

O período de florescimento foi diferenciado entre as cultivares e entre os níveis do fator indutor de brotação estudados (Figura 1). As plantas do tratamento testemunha tiveram maior duração do período de florescimento, quando comparadas às plantas tratadas com indutores de brotação. Segundo Soltész (2003), a duração do período de florescimento é influenciada pelas condições ambientais, visto que em condições de menor ocorrência de frio durante o período hibernal ocorre o aumento do período de florescimento. Petri e Leite (2004) abordam que o aumento do período de florescimento pode dificultar a realização de algumas práticas culturais como raleio e controle de doenças, devido à ocorrência de diferentes estádios fenológicos dentro de uma mesma planta. Apesar do acúmulo de frio ocorrido no ano em estudo $(876,46$ UF) ter sido inferior à média dos anos observados $(1047,51 \mathrm{UF})$, o período de florescimento não foi prolongado no tratamentotestemunha, limitando-se a 11 e 12 dias nas cultivares Imperial Gala e Fuji Suprema respectivamente. O uso de indutores de brotação promoveu redução significativa do período de florescimento nas cultivares estudadas, à exceção do tratamento com óleo mineral na cultivar Fuji Suprema, porém as maiores reduções foram obtidas nos tratamentos com cianamida hidrogenada associada ao óleo mineral.

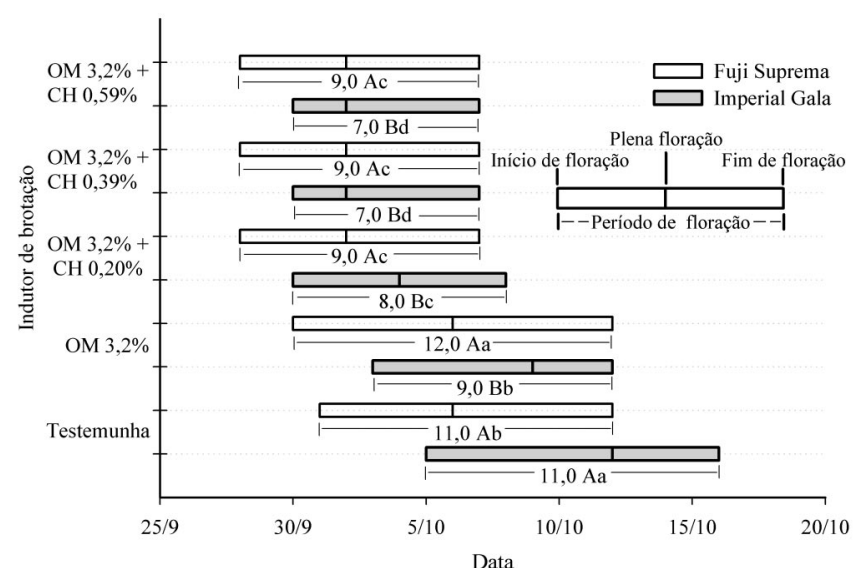

$\mathrm{OM}=$ óleo mineral; $\quad \mathrm{CH}=$ cianamida hidrogenada; $\quad$ Tratamentos aplicados em 05/09/2007; $\mathrm{F}$ (indutor de brotação $\mathrm{x}$ cultivar) $=48,58^{* *} \quad \mathrm{CV}(\%)=3,08$

** Valor de F significativo a $1 \%$ de probabilidade; Médias seguidas de mesma letra minúscula ** Valor de $\mathrm{F}$ significativo a $1 \%$ de probabilidade; Médias seguidas de mesma letra minúscula
dentro de cultivar, e médias seguidas de mesma letra maiúscula dentro de indutor de brotação, não diferem significativamente pelo teste Tukey a $5 \%$ de probabilidade de erro.

Figura 1. Período de florescimento de macieiras das cultivares Imperial Gala e Fuji Suprema tratadas com diferentes concentrações de cianamida hidrogenada e óleo mineral. Caçador (SC), 2008.

Em relação à época de florescimento, a aplicação de indutores de brotação reduziu o tempo transcorrido entre a aplicação dos tratamentos e ocorrência do pleno florescimento nas duas cultivares estudadas (Tabela 1). A aplicação de óleo mineral antecipou a floração das cultivares Fuji Suprema e Imperial Gala em um e dois dias em relação ao tratamento-testemunha respectivamente. Da mesma forma ao observado na 
duração do florescimento, as combinações de cianamida hidrogenada e óleo mineral foram os tratamentos mais efetivos na antecipação da floração, antecipando a floração em cinco dias na cultivar Imperial e em 3 dias na Fuji Suprema em relação às plantas não tratadas com indutores de brotação. Segundo Petri et al. (2006), a antecipação da floração propicia maior desenvolvimento dos frutos devido ao maior período de permanência dos frutos na planta, porém a antecipação da floração não corresponde à antecipação da maturação dos frutos na mesma proporção. Dessa forma, a antecipação da floração pelo uso de cianamida hidrogenada e óleo mineral em maiores concentrações pode ter maior relevância na sincronização da floração entre cultivares de interesse e suas polinizadoras do que propriamente antecipar a maturação dos frutos.

Tabela 1. Intervalo entre aplicação dos tratamentos e início da floração, em dias, de macieiras das cultivares Imperial Gala e Fuji Suprema tratadas com diferentes concentrações de cianamida hidrogenada (CH) e óleo mineral (OM). Caçador (SC), 2008

\begin{tabular}{|c|c|c|}
\hline \multirow{2}{*}{ Tratamento } & \multicolumn{2}{|c|}{ Intervalo entre aplicação dos tratamentos e início da floração } \\
\hline & Imperial Gala & Fuji Suprema \\
\hline & 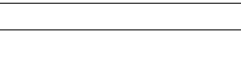 & 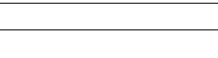 \\
\hline Testemunha & $30,0 \mathrm{Aa}$ & $26,0 \mathrm{Ba}$ \\
\hline OM 3,2\% & $28,0 \mathrm{Ab}$ & $25,0 \mathrm{Bb}$ \\
\hline $\mathrm{OM} 3,2 \%+\mathrm{CH} 0,20 \%$ & $25,0 \mathrm{Ac}$ & $23,0 \mathrm{Bc}$ \\
\hline $\mathrm{OM} 3,2 \%+\mathrm{CH} 0,39 \%$ & $25,0 \mathrm{Ac}$ & $23,0 \mathrm{Bc}$ \\
\hline $\mathrm{OM} 3,2 \%+\mathrm{CH} 0,59 \%$ & $25,0 \mathrm{Ac}$ & $23,0 \mathrm{Bc}$ \\
\hline Média Geral & 26,6 & 24,0 \\
\hline $\mathrm{CV}(\%)=1,12$ & \multicolumn{2}{|c|}{ F (indutor de brotação $x$ cultivar) $=29,90^{* *}$} \\
\hline
\end{tabular}

* Valor de F significativo a 1\% de probabilidade. Médias seguidas da mesma letra maiúscula na linha, e médias seguidas da mesma letra minúscula na coluna, não diferem estatisticamente pelo teste Tukey a 5\% de probabilidade de erro.

Observando-se a resposta das cultivares estudadas dentro dos mesmos níveis do fator indutor de brotação (Figura 1), constatou-se que nos tratamentos com indutores de brotação houve maior coincidência nas datas de plena floração entre as cultivares Imperial Gala e Fuji Suprema. A antecipação associada à redução do período de florescimento proporcionada pela utilização de indutores de brotação, principalmente nas combinações de cianamida hidrogenada e óleo mineral, aumentou a sincronização do florescimento entre cultivares, corroborando com os resultados obtidos por Petri et al. (1996) e Petri et al. (2006).

O comportamento diferenciado entre os níveis do fator indutor de brotação quanto à época de florescimento evidencia a importância do uso de indutores de brotação como estratégia de manejo para maximizar a polinização, através da maior sincronização da floração entre cultivares de importância comercial e suas polinizadoras. EREZ (2000) e Soltész (2003) abordam que o aumento da coincidência de floração entre cultivares pode ser obtido como o uso de indutores de brotação, através da antecipação do florescimento das cultivares de florescimento tardio.
A brotação de gemas axilares foi maximizada pela aplicação de indutores de brotação (Tabela 2). As plantas do tratamento testemunha apresentaram $13,0 \%$ e $20,7 \%$ de brotação das gemas axilares nas cultivares Imperial Gala e Fuji Suprema respectivamente. A aplicação de óleo mineral promoveu aumento da brotação das gemas axilares, sendo o aumento mais pronunciado o da cultivar Fuji Suprema com 50,8\% de gemas axilares brotadas enquanto o da cultivar Imperial Gala foi apenas de $28,4 \%$. Para ambas as cultivares estudadas, os maiores percentuais de brotação foram obtidos nos tratamentos com cianamida hidrogenada e óleo mineral, superiores a $73,0 \%$. Não houve diferença significativa entre cultivares dentro das combinações de cianamida hidrogenada e óleo mineral.

As cultivares estudadas foram responsivas ao aumento das doses de cianamida hidrogenada associada ao óleo mineral quanto a brotação de gemas axilares, conforme exposto na figura 2. Para a cultivar Imperial Gala foi observada resposta quadrática diante do aumento das doses de cianamida hidrogenada, com máxima brotação de gemas axilares (ponto de máxima $=-b / 2 c$ ) na concentração de $0,44 \%$ de cianamida hidrogenada associado a 3,2\% de óleo mineral. 


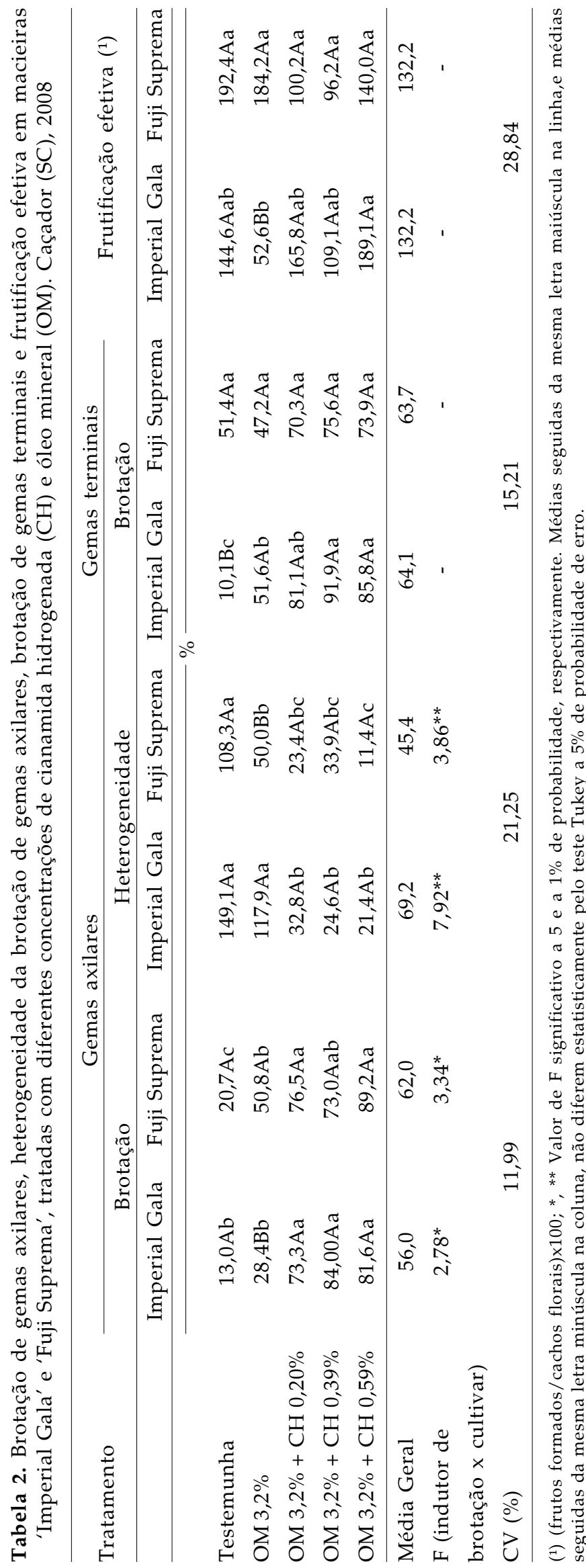

$\mathrm{Na}$ cultivar Fuji Suprema observou-se resposta linear ao aumento das concentrações de cianamida, indicando que pode ser obtido aumento da brotação de gemas axilares com a utilização de concentrações de cianamida hidrogenada superiores às utilizadas neste estudo.

Por meio do parâmetro heterogeneidade da brotação de gemas axilares foi possível verificar a existência de variabilidade no nível de brotação de gemas axilares entre diferentes ramos amostrados em uma mesma planta (Tabela 2). Leite (2004) e Leite et al. (2006) abordam que frutíferas temperadas cultivadas em condições subtropicais, onde o requerimento em frio não é satisfeito, proporcionam baixo nível de brotação associada à elevada heterogeneidade da brotação e floração ao longo dos ramos. Para Leite (2004; 2005), a heterogeneidade da floração e brotação manifesta-se temporalmente, caracterizada pela presença de gemas em vários estádios de desenvolvimento no mesmo momento e, espacialmente, mediante a formação de um gradiente anormal de brotação e floração ao longo de um mesmo ramo.

Neste estudo, verificou-se elevada heterogeneidade da brotação entre ramos de uma mesma planta no tratamento testemunha, sendo observados índices de heterogeneidade de brotação de gemas axilares de $149,06 \%$ e $108,32 \%$ nas cultivares Imperial Gala e Fuji Suprema, respectivamente (Tabela 2). A alta variabilidade nos percentuais de brotação de gemas axilares observada no tratamentotestemunha indica baixa uniformidade da brotação dentro de uma mesma planta. A aplicação dos indutores de brotação proporcionou redução dos índices de heterogeneidade da brotação de gemas axilares, fazendo com que nos diferentes ramos da planta notem-se índices de brotação similares. Esta resposta evidencia o efeito positivo da utilização de indutores de brotação na uniformização da brotação de gemas axilares em macieira. Na cultivar Imperial Gala, nas plantas tratadas com óleo mineral 3,2\% ocorrem índices de heterogeneidade da brotação superiores a $117,93 \%$, não diferindo significativamente da testemunha, indicando baixa eficiência deste produto na uniformização da brotação para esta cultivar. Já para a cultivar Fuji Suprema, a aplicação de óleo mineral reduziu os índices de heterogeneidade de $108,32 \%$ para $50,03 \%$. Assim como observado no percentual de brotação de gemas axilares, as combinações de cianamida hidrogenada e óleo mineral foram os tratamentos de maior efetividade na uniformização da brotação. Verificouse efeito significativo do aumento das concentrações de cianamida hidrogenada quando associada ao óleo mineral a 3,2\% sobre o índice de heterogeneidade da 
brotação, observando sua diminuição diante do aumento das doses para as duas cultivares em estudo.

Em relação à brotação de gemas terminais, nas cultivares estudadas houve respostas diferenciadas à aplicação dos indutores de brotação (Tabela 2). $\mathrm{Na}$ cultivar Imperial Gala, a aplicação de indutores de brotação proporcionou aumento significativo da brotação de gemas terminais. O tratamento com óleo mineral 3,2\% elevou a brotação de gemas terminais de $10,10 \%$ para $51,55 \%$. Os resultados observados com a cultivar Imperial corroboram com PeTRI et al. (2006), quando afirmam que o óleo mineral é efetivo no aumento da brotação de gemas terminais, porém seu efeito na brotação de gemas axilares é inferior à associação de óleo mineral e cianamida hidrogenada. Os tratamentos em que foram obtidos as maiores porcentagens de brotação de gemas terminais na cultivar Imperial Gala foram os tratamentos com cianamida hidrogenada associados ao óleo mineral, proporcionando brotação superior a $81,08 \%$. Na cultivar Fuji Suprema, não foi visualizado aumento significativo da brotação de gemas terminais pelo uso de indutores de brotação em relação ao tratamento testemunha, apesar das médias dos tratamentos com cianamida hidrogenada serem superiores numericamente.

Constatou-se efeito significativo do aumento das doses de cianamida hidrogenada junto ao óleo mineral sobre a brotação de gemas terminais, cuja resposta foi quadrática na cultivar Imperial Gala, sendo a dose de $0,44 \%$ de cianamida hidrogenada associada a 3,2\% de óleo mineral a que proporcionou a máxima brotação (ponto de máxima $=-\mathrm{b} / 2 \mathrm{c}$ ) (Figura 2). A resposta observada nas gemas axilares para a cultivar Fuji Suprema foi linear diante do aumento das doses de cianamida hidrogenada.

Observando o comportamento das cultivares estudadas no tratamento testemunha, verificou-se que houve maior porcentagem de brotação na cultivar Fuji Suprema tanto nas gemas axilares como nas gemas terminais, em relação à Imperial Gala. Este comportamento evidencia a maior necessidade da realização de tratamentos para aumentar a brotação na cultivar Imperial Gala do que na cultivar Fuji Suprema.
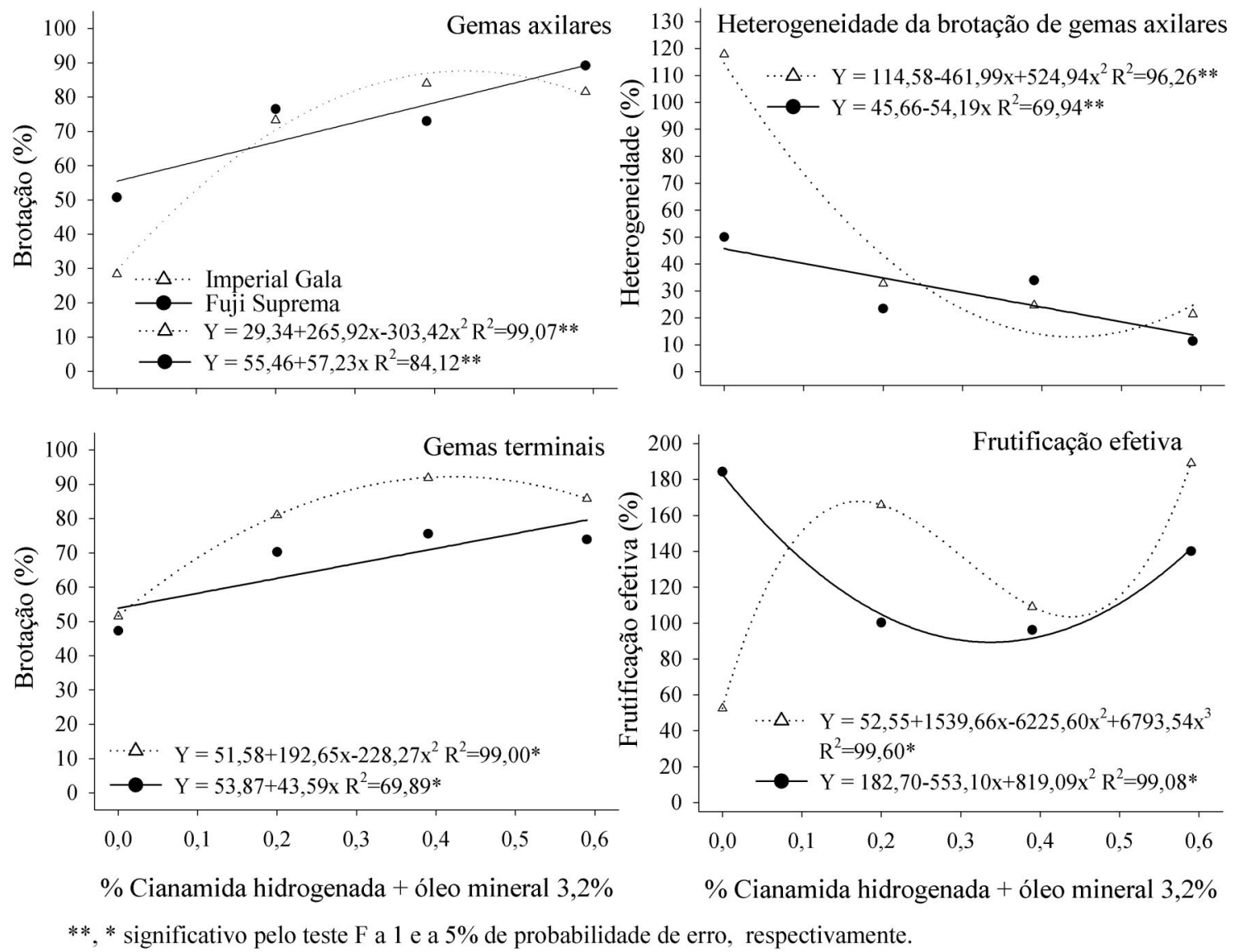

Figura 2. Efeito de diferentes concentrações de cianamida hidrogenada associada a óleo mineral 3,2\% na brotação de gemas axilares, heterogeneidade da brotação de gemas axilares, brotação de gemas terminais e frutificação efetiva em macieiras 'Imperial Gala' e 'Fuji Suprema'. Caçador (SC), 2008 
A frutificação efetiva foi diferenciada entre níveis do fator indutor de brotação, sendo verificada diferença significativa entre as cultivares unicamente no tratamento com óleo mineral $3,2 \%$ (Tabela 2). As plantas do tratamento-testemunha tiveram frutificação efetiva de $144,64 \%$ e $192,41 \%$, respectivamente, para as cultivares Imperial Gala e Fuji Suprema. Erez (2000) e Petri e Leite (2004) abordam a possibilidade de redução da frutificação efetiva devido à não-sincronização de polinização entre cultivares em condições de insuficiente acúmulo de frio durante o período hibernal. Os altos valores de frutificação efetiva obtidos no tratamento-testemunha indica que não houve problemas relacionados à polinização, mesmo sendo menor a coincidência de florescimento neste tratamento em comparação aos tratamentos com indutores de brotação.

Para a cultivar Imperial Gala, as combinações de cianamida hidrogenada e óleo mineral não diferiram significativamente da testemunha quanto à frutificação efetiva, com valores superiores a 109,09\%. O menor desempenho quanto à frutificação efetiva foi obtido com óleo mineral 3,2\%. Em função de não terem sido identificados problemas em relação à coincidência de floração, sugere-se que a menor frutificação efetiva possa ser advinda da menor intensidade de floração da cultivar Imperial Gala neste tratamento, como relatado por Petri e LeIte (2004). A menor intensidade de floração nas plantas tratadas com óleo mineral 3,2\% pode estar associada ao predomínio da brotação de gemas vegetativas neste tratamento.

Não foi verificada diferença significativa entre os níveis do fator indutor de brotação na frutificação efetiva da cultivar Fuji Suprema, porém observa-se que a aplicação dos indutores de brotação promoveu redução da frutificação efetiva em relação à testemunha, sobretudo nos tratamentos com cianamida hidrogenada. ELAGAMY et al. (2007) verificaram efeito negativo dos tratamentos com cianamida hidrogenada sobre a frutificação efetiva da cultivar 'Anna'. De acordo com EREZ (2000), em determinadas situações podese obter drástica redução da frutificação efetiva pelo uso de indutores de brotação, devido à competição nutricional estabelecida entre drenos vegetativos e reprodutivos. O início do desenvolvimento de folhas e de frutos é dependente das reservas acumuladas durante a estação de crescimento anterior (FAUST, 2000). Como o uso de indutores de brotação promoveu rápida brotação, tanto de gemas vegetativas como floríferas, a disponibilização de reservas para o desenvolvimento de novas estruturas pode ter sido insuficiente, acarretando a redução da frutificação efetiva como apontado por EREZ (2000).

Nas cultivares estudadas as respostas foram diferenciadas no número e na massa de frutos por área de secção transversal do tronco diante dos tratamentos com indutores de brotação (Tabela 3).

Na cultivar Imperial Gala, os tratamentos com indutores de brotação, à exceção da cianamida hidrogenada $0,39 \%$ associada a $3,2 \%$ de óleo mineral, aumentaram o número de frutos por área de secção transversal do tronco em relação à testemunha, repercutindo em maior massa de frutos produzida nestes tratamentos. NUNES et al. (2001) também atribuem a maior massa de frutos produzida ao maior desenvolvimento da área foliar e à maior capacidade de produção de fotoassimilados nas plantas tratadas com indutores de brotação para o número de frutos por área de secção transversal do tronco. Não houve diferenças significativas entre os diferentes tratamentos realizados na cultivar Fuji Suprema (Tabela 3). Comparando os indutores de brotação ao tratamento testemunha não foi observada diferença significativa quanto à massa de frutos por área de secção do tronco na cultivar Fuji Suprema (Tabela 3). A resposta dos indutores de brotação na produção de frutos é dependente das condições climáticas ocorrentes durante o período de desenvolvimento dos frutos, pois em condições climáticas adequadas não se observa acentuada diferença na produção de frutos pelo uso de indutores de brotação, como relatado por BотеLHo et al. (2002), Petri et al. (2006) e Werle et al. (2008).

Em relação à massa média dos frutos, as plantas tratadas com óleo mineral a 3,2\% tiveram o maior desempenho na cultivar Imperial, sendo significativamente superior aos demais tratamentos. Na cultivar Fuji Suprema, a massa média dos frutos foi superior nas plantas não tratadas com indutores de brotação (Tabela 3), sendo observado decréscimo da massa dos frutos diante do aumento das doses de cianamida hidrogenada junto ao óleo mineral. A maior massa média dos frutos observada nas plantas testemunhas da cultivar Fuji Suprema pode estar associada ao tipo de gema em que houve o predomínio na produção de frutos, prevalecendo a frutificação em brindilas no tratamento testemunha, enquanto nos tratamentos de cianamida hidrogenada e óleo mineral, que proporcionaram maior brotação de gemas, ocorreu intensa frutificação em esporões. 


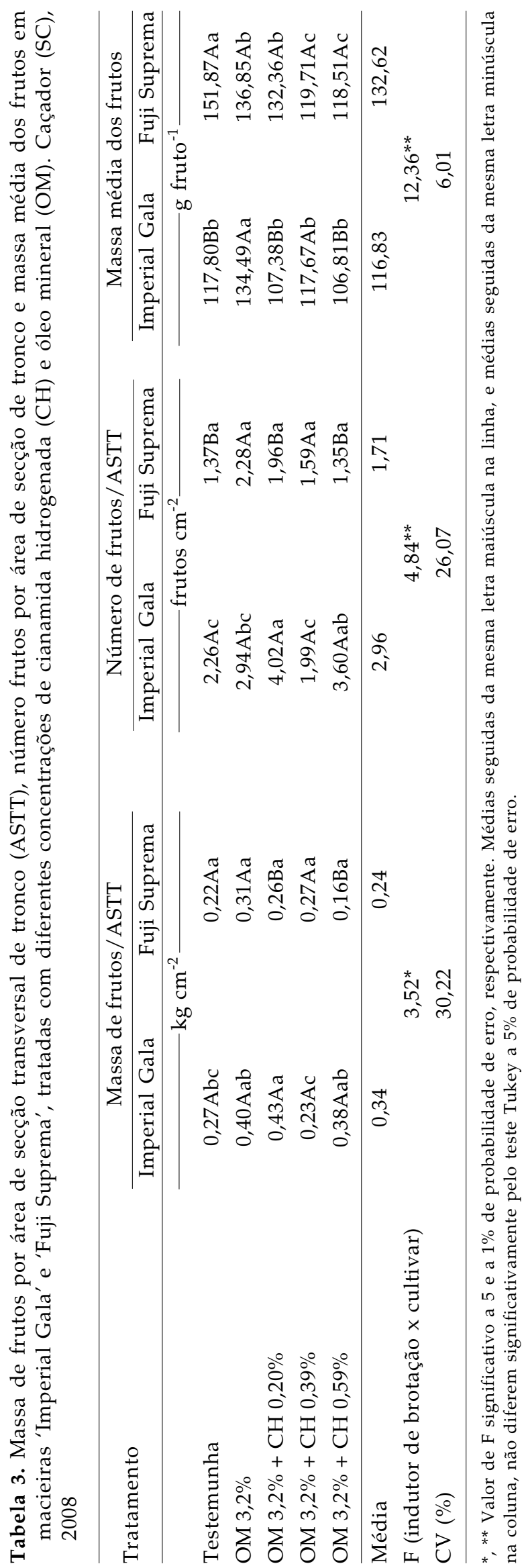

Nachtigall (2000), estudando as estruturas de frutificação das cultivares Gala e Fuji, observou que frutos oriundos de gemas terminais em brindilas têm maior potencial de desenvolvimento, com maior massa final quando comparado a frutos produzidos em gemas axilares e em esporões. Como no tratamento testemunha, a brotação ocorreu predominantemente nas gemas terminais, a maior parte dos frutos originou-se deste tipo de estrutura de frutificação, justificando a maior massa média observada dos frutos. O mesmo comportamento não foi verificado na cultivar Imperial Gala, devido a baixa brotação observada tanto nas gemas axilares como nas gemas terminais. A aplicação de óleo mineral a 3,2\% teve baixa efetividade na brotação de gemas axilares, mas incrementou a brotação de gemas terminais e, por conseguinte, aumentou a proporção de frutos localizados nestas estruturas, explicando o aumento da massa média dos frutos obtida na cultivar Imperial Gala. A menor massa média dos frutos nas combinações de cianamida hidrogenada e óleo mineral em ambas as cultivares pode estar associado à uniformização da brotação e ao aumento da proporção de gemas brotadas em todos os tipos de estrutura de frutificação presentes na planta, ocorrendo a frutificação em distintas estruturas, com potenciais diferenciados de desenvolvimento dos frutos.

Apesar de verificada a produção de frutos e massa média dos frutos similar em plantas tratadas e não tratadas com indutores de brotação, não se dispensam os tratamentos para indução da brotação. Como relatado por PetRI et al. (2006), a resposta dos indutores de brotação na produção de frutos é diferenciada ao longo dos anos, porém os mesmos devem ser utilizados regularmente, visto que a falta de brotação de gemas terminais e axilares tem efeito cumulativo ao longo dos anos, reduzindo a formação de novas estruturas de frutificação, podendo acarretar em diminuição da produção.

\section{CONCLUSÕES}

1. A aplicação dos indutores de brotação, sobretudo as combinações de cianamida hidrogenada e óleo mineral, antecipa e reduz o período de florescimento, aumentando a coincidência de florescimento das cultivares Imperial Gala e Fuji Suprema.

2. Os indutores de brotação uniformizam e aumentam a brotação de gemas axilares e terminais, obtendo-se máxima brotação na cultivar Imperial Gala com $0,44 \%$ de cianamida hidrogenada e 3,2\% de óleo mineral. 
3. As combinações de cianamida hidrogenada e óleo mineral não diferem da testemunha quanto à frutificação efetiva nas cultivares avaliadas, porém observa-se que o aumento das doses de cianamida hidrogenada tende a diminuir a frutificação efetiva.

4. Observam-se respostas diferenciadas entre tratamentos quanto à produção e à massa média dos frutos, podendo ser atribuídas ao predomínio da produção de frutos em distintas estruturas de frutificação.

\section{AGRADECIMENTOS}

Os autores agradecem ao Conselho Nacional de Desenvolvimento Científico e Tecnológico (CNPq) pela bolsa de Doutorado concedida ao primeiro autor.

\section{REFERÊNCIAS}

BANZATTO, D.A.; KRONKA, S.N. Experimentação agrícola. 3.ed. Jaboticabal: FUNEP, p. 54-59, 1995.

BOTELHO, R.V.; PIRES, E.J.P.; TERRA, M.M. Brotação e produtividade de videiras da cultivar Centenial Seedless (Vitis vinifera L.) tratadas com cianamida hidrogenada na região noroeste do Estado de São Paulo. Revista Brasileira de Fruticultura, v.24, p.611-614, 2002.

BULON, L.; FAUST, M. New aspects of bud dormancy in apple trees. Acta Horticulturae, v.395, p. 105-111, 1995.

CAMILO, A.P.; DENARDI, F. Cultivares: Descrição e comportamento no sul do Brasil. In: EPAGRI. A cultura da macieira. Florianópolis. p.113-168, 2006.

CARVAJAL-MILLÁN, E.; GARDEA, A.A.; RASCÓN-CHU, A.; OROZZO, J.A.; LEÓN, N.P.; MÁRQUEZ-ESCALANTE, J.A.; CHACÓN A.R.;. GUERRERO, V.M. Respiratory response of apple buds treated with budbreaking agents. Thermochimica Acta, v.457, p.109-112, 2007.

DOKOOZLIAN, N.K.; WILLIAMS, L.E.; NEJA, R.A. Chilling exposure and hydrogen cyanamide interact in breaking dormancy of grape buds. HortScience, v.30, p.1244-1247, 1995.

EBERT, A.; PETRI, J.L.; BENDER, R.J.; BRAGA, H.J. First experiences with chill units models is southern Brazil. Acta Horticulturae, v.184, p. 9-96, 1986.

EL-AGAMY, S.Z., MOHAMED, A.K.A., MOSTAFA, F.M.A. AND ABDALLAH, A.Y. Effect of $\mathrm{GA}_{3}$, Hydrogen Cyanamid And Decapitation on Budbreak and Flowering of Two Apple Cultivars under the Warm Climate of Southern Egypt. Acta Horticulturae, v.565, p.109-114, 2001.

EREZ, A. Bud dormancy: phenomenon, problems and solutions in the tropics and subtropics. In: EREZ, A. Temperate fruit crops in warm climates. Boston, London: Kluwer Academic Publishers, 2000. p.17-48.
FAUST, M. Physiological considerations for growing temperate-zone fruit crops in warm climates. In.: Temperate fruits crop in warm climates. Boston, London: Kluwer Academic Publishers, 2000. p.305-342.

LEITE, G.B. Evolution dês Etats dês Bourgeons et de leur heterogeneite Le Long Du Rameau d'un de pecher sous differents regimes de temperatures apres l'instalation de l'endodormance. 2004, 168 p. Thèse. Université Blaise Pascal Clermont-Ferrand II, 2004.

LEITE, G. B. Evolução da dormência e heterogeneidade da brotação In: Encontro Nacional Sobre Fruticultura de Clima Temperado, Fraiburgo, 8. Anais... Caçador: Epagri, 2005. vol.1 (Palestras), p. 269-275.

LEITE, G.B.; BONHOMME, M.; PUTTI, G.L.; PETEL, G.; PETRI, J.L.; RAGEAU, R. Physiological and biochemical evolution of peach leaf buds during dormancy course under two contrasted temperature patterns. International Journal of Horticultural Science. v.12, n.4, p.15-19, 2006.

NACHTIGALL, G.R. Estruturas de frutíferas na qualidade de maçãs, cultivares Gala e Fuji. 2000, 57p. Tese (Doutorado em Agronomia-Fruticultura de Clima Temperado)-Faculdade de Agronomia Eliseu Maciel, Universidade Federal de Pelotas, 2000.

NUNES, J.L.S.; MARODIN, G.A.B.; SARTORI, I.A. Cianamida hidrogenada, thidiazuron e óleo mineral na quebra de dormência e na produção do pessegueiro cv. Chiripá. Revista Brasileira de Fruticultura, v. 23, p. 493-496, 2001.

PETRI, J.L. Alternativas para quebra de dormência em fruteiras de clima temperado. In: Encontro Nacional Sobre Fruticultura de Clima Temperado, Fraiburgo, 8. Anais... Caçador: Epagri, vol.1(Palestras), 2005. p.125-133.

PETRI, J.L. Fatores edafoclimáticos. In: EPAGRI. A cultura da macieira. Florianópolis, 2006. p.105-112.

PETRI, J.L.; LEITE, G.B. Consequences of Insufficient Winter Chilling on Apple Tree Bud-break. Acta Horticulturae, v. 662, p.53-60, 2004.

PETRI, J.L.; PALLADINI, L.A.; POLA, A.C. Dormência e indução a brotação em macieira. In: EPAGRI. A cultura da macieira. Florianópolis, 2006. p.261-297.

PETRI, J. L.; PALLADINI, L. A.; SCHUCK, E.; DUCROQUET, J. P.; MATOS, C. S.; POLA, A. C. Dormência e indução da brotação de fruteiras de clima temperado. Florianópolis: EPAGRI, 1996.110p.

SANHUEZA, R.M.V.; PROTAS, J.F.S.; FREIRE, J.M.. Manejo da Macieira no Sistema de Produção Integrada de Frutas. Bento Gonçalves: Embrapa Uva e Vinho, 2006. 164p.

SAS LEARNING EDITION. Getting started with the SAS learning edition. Cary, 2002. 200p.

SOLTÉSZ, M. Apple. In: KOZNA, P.; NYÉKI, J.; SOLTÉSZ, M.; SZABO, Z. Floral Biology, Pollination and Fertilisation Zone Fruit Species and Grape. Budapest: Akadémia Kiadó, 2003. p.237-316. 
WERLE, T.; GUIMARAES, V.F.; DALASTRA, I.M.; ECHER, M.M; PIO, R. Influência da cianamida hidrogenada na brotação e produção da videira 'Niagara Rosada' na região oeste do Paraná. Revista Brasileira de Fruticultura, v.30, p.20-24, 2008.

WILLIAMSON, J.G; MAUST, B.E.; MILLER, P.; KREWER, G. Hydrogen cyanamide accelerates vegetative budbreak and shortens fruit development period of blueberry. Proceedings of the Florida State Horticultural Society. v.115, p.100-104, 200 